\title{
Effective Degradation of Rh 6G Using Montmorillonite-Supported Nano Zero-Valent Iron under Microwave Treatment
}

\author{
Wenxiu Rao ${ }^{1}$, Hao Liu ${ }^{2, *}$, Guocheng Lv ${ }^{1, *}$, Danyu Wang ${ }^{1}$ and Libing Liao ${ }^{1, *}$ \\ 1 Beijing Key Laboratory of Materials Utilization of Nonmetallic Minerals and Solid Wastes, \\ National Laboratory of Mineral Materials, School of Materials Science and Technology, \\ China University of Geosciences, Beijing 100083, China; 2103170029@cugb.edu.cn (W.R.); \\ 13020023660@163.com (D.W.) \\ 2 School of Science, China University of Geosciences, Beijing 100083, China \\ * Correspondence: 2014010007@cugb.edu.cn (H.L.); guochenglv@cugb.edu.cn (G.L.); clayl@cugb.edu.cn (L.L.)
}

Received: 18 October 2018; Accepted: 5 November 2018; Published: 7 November 2018

check for updates

\begin{abstract}
Nano zero-valent iron has drawn great attention for the degradation of organic dyes due to its high reactivity, large specific surface area, lightweight, and magnetism. However, the aggregation and passivation of iron nanoparticles may prohibit the wide use of it. A new composite material was prepared by loading nano zero-valent iron (nZVI) on montmorillonite (MMT) to overcome the above shortcomings and it was further used for the removal of Rhodamine 6G (Rh 6G) under microwave treatment in the present work. The effects of various parameters, including the initial concentration of $\mathrm{Rh}$ 6G, microwave power, and $\mathrm{pH}$ value were investigated. The new composite material (nZVI/MMT) showed an excellent degradation ability for removing Rh 6G, and the removal amount reached $500 \mathrm{mg} / \mathrm{g}$ within $15 \mathrm{~min}$. The degradation rate reached $0.4365 \mathrm{~min}^{-1}$, significantly higher than most previous reports using other removal methods for Rh 6G.
\end{abstract}

Keywords: nano zero-valent iron; montmorillonite; organic dyes; Fenton-like reaction; microwave

\section{Introduction}

Printing and dyeing wastewaters are the major sources for water pollution and elsewhere [1]. Every year, a large amount of these wastewaters with high levels of organic pollutants and complex components are discharged [2], which will greatly affect the water security of living creatures [3]. In addition, large amounts of pollutants are produced during the production of organic dyes in the textile industry. Serious environmental pollution will occur without treatment [4]. However, they are difficult to be naturally biodegraded [5]. Therefore, seeking efficient and economical treatment methods for dye wastewater are urgently needed in the dye production and printing/dyeing industries.

Many dye wastewater treatment technologies have been explored [6], including physical methods [7], chemical methods [8], biological methods [9], and so on. Of these methods, the Fenton method is an effective method for dye degradation [10]. The traditional Fenton method utilizes $\mathrm{Fe}^{2+}$ to catalyze $\mathrm{H}_{2} \mathrm{O}_{2}$ to produce hydroxyl radicals $(\bullet \mathrm{OH})$ with an oxidation-reduction potential of $2.80 \mathrm{~V} \mathrm{[11].} \mathrm{The} \mathrm{hydroxyl} \mathrm{radical} \mathrm{can} \mathrm{directly} \mathrm{degrade} \mathrm{most} \mathrm{of} \mathrm{the} \mathrm{organic} \mathrm{pollutants} \mathrm{[12].}$ Nevertheless, the traditional Fenton method requires a concentration of iron ions of 50-80 mg/L [13], which is much higher than the allowance of $2 \mathrm{mg} / \mathrm{L}$ of the EU Steering Committee's requirement. In addition, a large amount of iron sludge will be produced during the reaction [14], and the optimum $\mathrm{pH}$ value for the traditional Fenton method is 3 [15]. Thus, the $\mathrm{pH}$ value of wastewater needs to be adjusted, increasing the operating costs of water treatment. 
Fenton-like reactions can occur under neutral conditions [16]. The Fenton reaction nano zero-valent iron (nZVI) has degraded many organic substances $[17,18]$. In recent years, nZVI has attracted much attention due to the high specific surface area, large surface energy, and excellent performance for treating contaminants [19]. The nZVI had good results in the treatment of printing and dyeing wastewater [20], heavy metals [21,22], chlorinated organic compounds [23,24], organic insecticides $[25,26]$, and other areas $[27,28]$. However, nZVI is highly reactive and easily oxidized [29], limiting its practical applications. Montmorillonite (MMT) is a 2:1 type of mineral, which consists of two sheets of silicon tetrahedron and a middle sheet of aluminum octahedron [30]. Because of its unique layered structure, MMT can adsorb a variety of organic contaminants, such as chlorpheniramine [31], benzothiazolium [32], and Rh 6G [33]. In addition, the cations are stably arranged in the interlaminar domain of the MMT lamellae due to a strong electrostatic attraction force between the cations and interlaminar layer [34]. Because more and more composites are used as catalysts $[35,36]$, we expect that the MMT can protect the nZVI to avoid its oxidation by loading nZVI into MMT lamellae to form the composite.

Using light [37], ultrasound [38], or microwave [39] can speed up the Fenton reaction speed. In these methods, because of the strong penetrating effect of the microwave, it can directly heat the reactant molecular and provide more energy to the reaction system [40]. During these interactions, the activation energy of the reaction and the chemical bond strength of the molecular can be reduced, while the production rates of $\mathrm{Fe}^{2+}$ and $\bullet \mathrm{OH}$ speed up, leading to the acceleration of the rate of the degradation reaction [41].

In the present work, nZVI/MMT was synthesized using a liquid phase reducing method and used as a degradable material to deal with Rh 6G under microwave treatment. The factors that affect the reaction efficiency and rate were discussed in detail. The removal amount of $\mathrm{Rh} 6 \mathrm{G}$ reached $500 \mathrm{mg} / \mathrm{g}$ within $15 \mathrm{~min}$ and its degradation rate reached $0.4365 \mathrm{~min}^{-1}$, significantly higher than previous reports using other removal methods for Rh 6G. This work provides a good reference for the effective treatment of printing and dyeing wastewater using nZVI materials.

\section{Materials and Methods}

\subsection{Materials}

Iron(III) chloride hexahydrate $\left(\mathrm{FeCl}_{3} \cdot 6 \mathrm{H}_{2} \mathrm{O}\right)$, sodium borohydride $\left(\mathrm{NaBH}_{4}\right)$, hydrochloric acid $(\mathrm{HCl})$, sodium hydroxide $(\mathrm{NaOH})$, indolepropionic acid (IPA), p-benzoquinone (PBQ), triethanolamine (TEOA), and silver nitrate $\left(\mathrm{AgNO}_{3}\right)$ were bought from Beijing Chemical Workstation (Beijing, China). The Rh 6G was from Aladdin Holdings Group (Beijing, China). The MMT was obtained from Inner Mongolia Ningcheng Tianyu Bentonite Technology Co., Ltd. (Ningcheng, China), and used without further purification. The chemicals were all of the analytical grade. All of the solutions were formulated with distilled water.

\subsection{Synthesis of $n Z V I / M M T$}

In a three-necked flask, $10 \mathrm{~g}$ of $\mathrm{FeCl}_{3} \cdot 6 \mathrm{H}_{2} \mathrm{O}$ was dissolved in the solvent containing $30 \mathrm{~mL}$ of deionized water and $20 \mathrm{~mL}$ of ethanol. Then $5 \mathrm{~g}$ of MMT was added to the solution. $\mathrm{NaBH}_{4}$ solution ( $8 \mathrm{~g}$ dissolved in $40 \mathrm{~mL}$ distilled water) was added dropwise into the mixture that had been high speed stirred for $4 \mathrm{~h}$ and blown with high purity nitrogen for $30 \mathrm{~min}$. After the addition of $\mathrm{NaBH}_{4}$, the mixture was stirred for another $40 \mathrm{~min}$ at room temperature in nitrogen. The solid part was freeze-dried after centrifugation.

\subsection{Characterizations}

The structures of the samples were determined by the X-ray diffractometer (XRD) with a CuK $\alpha$-radiation at $30 \mathrm{kV}$ and $20 \mathrm{~mA}$ (Rigaku D/Max-IIIa X-ray diffractometer, Rigaku, Tokyo, Japan). Samples were scanned from $3^{\circ}$ to $70^{\circ}$ at a speed of $8^{\circ} \mathrm{min}^{-1}$ with a scanning step length of 
$0.01^{\circ}$. TEM (transmission electron microscopy) tests of the MMT and nZVI/MMT were carried on a JEOL-2100 transmission electron microscope (JEOL, Tokyo, Japan) with an accelerating voltage of $200 \mathrm{kV}$. The sample powders were well dispersed in ethanol and dried on a copper grid supported carbon film before observation. Microwave absorption properties of the flexible absorbing film were analyzed using a microwave network analyzer N5244A (Agilent Technologies, Santa Clara, CA, USA). The frequency range was from 2 to $10 \mathrm{GHz}$. The coaxial wire method was adopted for the analyses.

\subsection{Rh 6G Removal Experiment}

Rh 6G was dissolved in distilled water to prepare the Rh 6G solution $(5000 \mathrm{mg} / \mathrm{L})$ and left to rest overnight. Zero point one grams of nZVI/MMT was added to $10 \mathrm{~mL}$ of Rh $6 \mathrm{G}$ stock solution in a glass beaker and stirred in batch experiments. Then the microwave reactor was used to treat the mixture under different microwave powers. After microwaving, the cooled slurry was centrifuged at $6000 \mathrm{rpm}$ for $5 \mathrm{~min}$. Then $10 \mathrm{~mL}$ aliquot of the supernatant was filtered with a syringe filter and transferred to a $50 \mathrm{~mL}$ colorimetric tube for UV-visible analysis at the end of the process. In the cycle test, nZVI/MMT was prepared using an $\mathrm{NaBH}_{4}$ reduction of the $\mathrm{Fe}^{3+}$ back to $\mathrm{Fe}^{0}$. All experiments were run in duplicates.

\section{Results and Discussion}

\subsection{Crystallization, Morphology and Valence States of nZVI/MMT}

We developed a new composite material for Rh 6G degradation under microwave treatment, and the composite material was synthesized using a liquid phase reducing method (Section 2.2) to load nZVI on MMT (Figure 1a), which greatly improved the antioxidant and anti-agglomerating ability of nZVI. The phase structures of the as-prepared MMT, nZVI, nZVI/MMT were examined by XRD (Figure $1 b$ ). The $2 \theta$ values in the XRD pattern of the nZVI/MMT locate at $5.89^{\circ}$ and $19.71^{\circ}$, corresponding to 001 and 100 basal planes of MMT (JCPDS No. 47-1097). The reflection at $44.7^{\circ}$ is owed to the 110 basal planes of $\mathrm{Fe}^{0}$ (JCPDS No. 06-0696). No iron oxide peak was found in the nZVI/MMT, indicating that the iron was not oxidized during the synthesis process, or only a very small portion of amorphous iron oxides formed. In addition, the pattern of nZVI/MMT is similar to that of pure MMT, suggesting that the structure of the nZVI/MMT remains before and after the loading of nZVI.

(a)

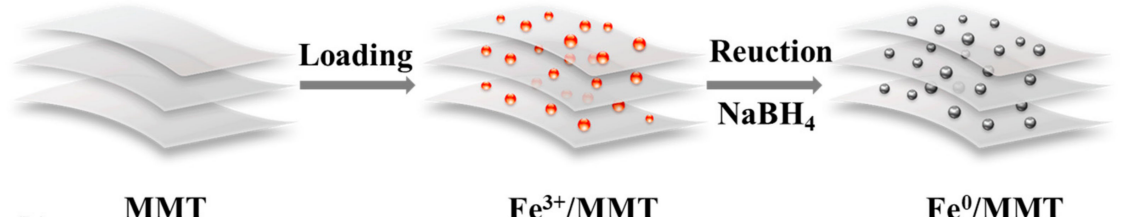

(b)

$\mathrm{Fe}^{3+} / \mathrm{MMT}$

$\mathrm{Fe}^{0} / \mathrm{MMT}$

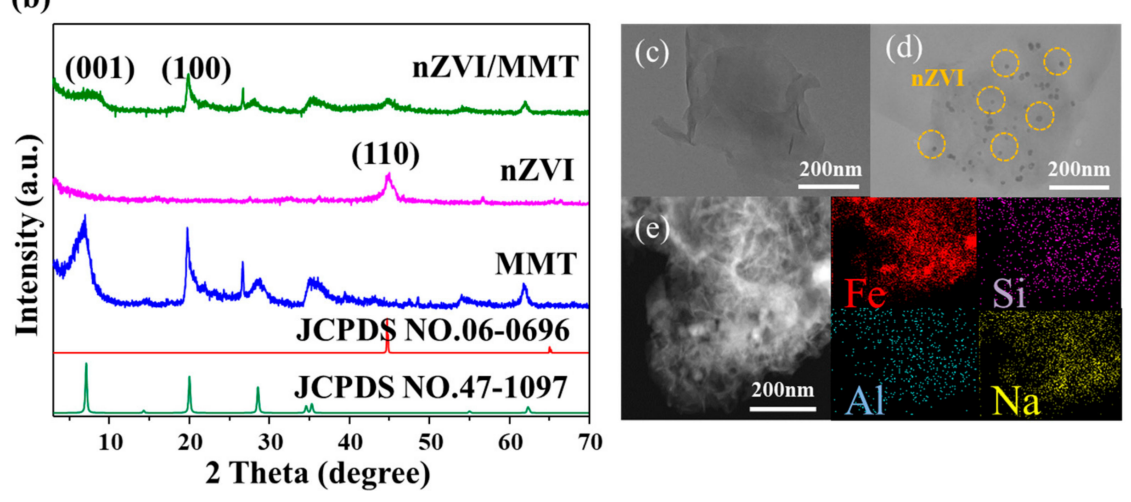

Figure 1. (a) Schematic for the synthesis of the nano zero-valent iron/montmorillonite (nZVI/MMT) composite; (b) X-ray diffraction patterns of MMT, nZVI and nZVI/MMT; (c) TEM image of MMT; (d) nZVI/MMT; (e) Energy dispersive spectrometer (EDS) element mapping image of nZVI/MMT. 
In order to further reveal the morphologies of the samples, TEM was carried out (Figure 1). Compared with pristine MMT (Figure 1c), lots of zero-valent iron nanoparticles with an average size of $15 \mathrm{~nm}$ are uniformly dispersed on the surface of nZVI/MMT (Figure 1d). This indicates that MMT could be used as a support to prevent the aggregation of nZVI. The energy dispersive spectrum analysis reveals that this sample composes of $\mathrm{Fe}, \mathrm{Si}, \mathrm{Al}, \mathrm{Na}$ elements and no impurities are found (Figure 1e).

The antioxidant ability of nZVI/MMT and nZVI was compared by observing their color change at different time slots in the air, as shown in Figure 2. Both fresh solutions are black. As time increases, due to the oxidation of nZVI, both solutions' color gradually become lighter. Nevertheless, the nZVI/MMT shows much better antioxidant ability than nZVI. For example, the black nZVI solution totally turns to yellow at $72 \mathrm{~h}$. In contrast, the nZVI/MMT solution just begins to turn to yellow at the same time, indicating that only a small portion of nZVI is oxidized at this moment. The above results prove that the zero valent iron loaded on the MMT is more difficult to be oxidized than the nZVI alone, which brings a big advantage for the application of nZVI/MMT.
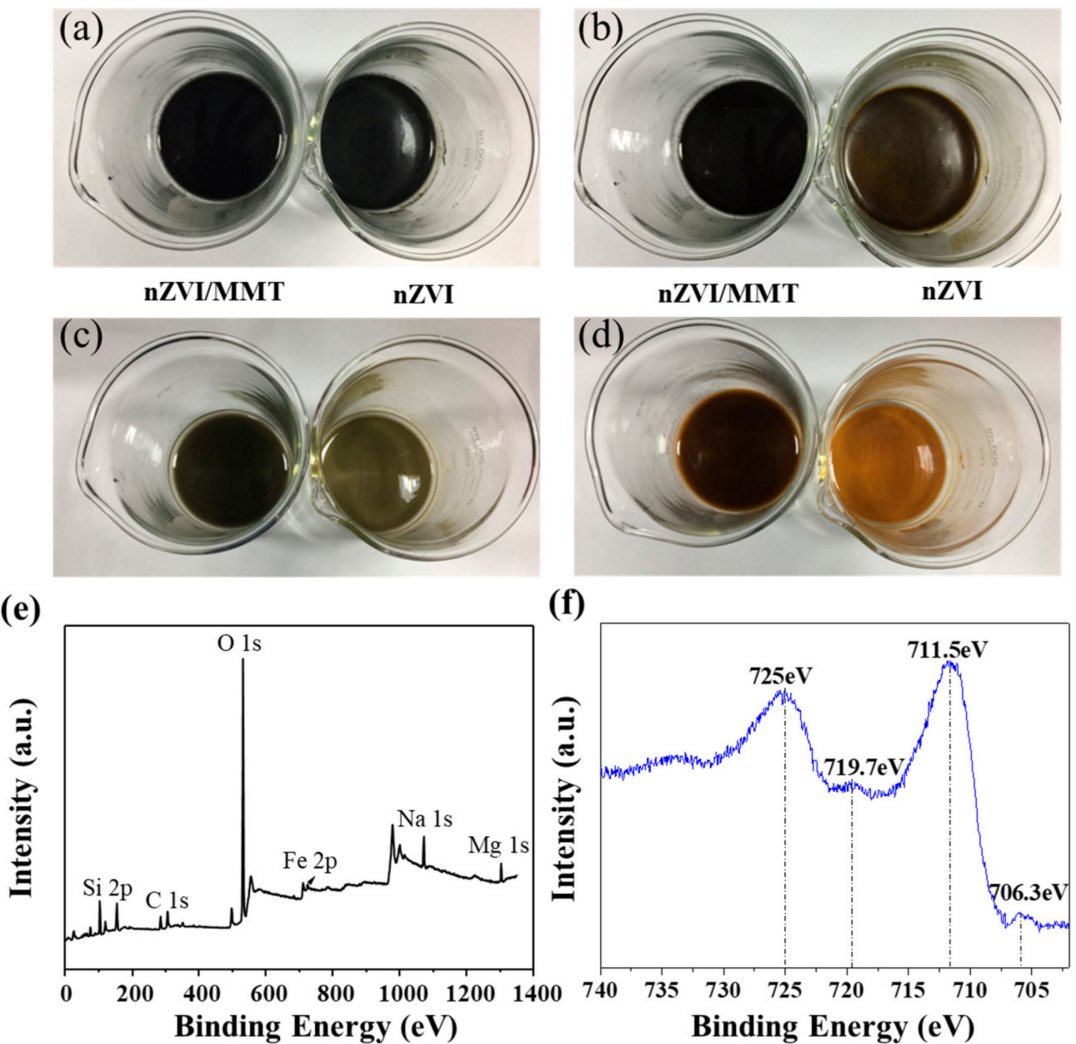

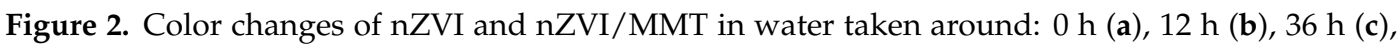
and $72 \mathrm{~h}(\mathrm{~d})$; X-ray photoelectron spectroscopy (XPS) survey spectrum of nZVI/MMT (e); and XPS fine spectrum of Fe $2 p(\mathbf{f})$.

The compositions and the valence of the iron on the surface of nZVI/MMT were analyzed using XPS technique. Figure 2e shows the survey spectrum of nZVI/MMT, revealing that the surface is composed of iron elements. Figure $2 \mathrm{f}$ shows the fine spectrum of Fe $2 \mathrm{p}$ of nZVI/MMT comprises four different peaks. The iron content of the composite material is $15.35 \%$, higher than pure MMT (2.01\%). The peaks at binding energies of $706.3 \mathrm{eV}$ and $719.7 \mathrm{eV}$ could be owed to the $2 \mathrm{p} 3 / 2$ and $2 \mathrm{p} 1 / 2$ peaks of $\mathrm{Fe}^{0}$, respectively [42]. The other two peaks at binding energies of $711.5 \mathrm{eV}$ and $725.0 \mathrm{eV}$ could be attributed to the $2 \mathrm{p} 3 / 2$ and $2 \mathrm{p} 1 / 2$ peaks of $\mathrm{Fe}(\mathrm{III})$, respectively, revealing that partial $\mathrm{Fe}^{0}$ on the surface had been oxidized to Fe(III). 


\subsection{Microwave Absorption Properties of nZVI/MMT}

Microwave treatment can cause heterogeneous localized heating, called "hot spots", which may significantly promote the rate of free radical generation [43]. The microwave network analysis characterizes the microwave absorption characteristics of nZVI/MMT nanocomposites. Generally speaking, the microwave absorbing performance of nZVI/MMT was characterized by the reflection loss (RL), which could also be determined by the complex permittivity and permeability for the given frequency and absorber thicknesses. The effective interaction between the complex permittivity and the permeability of nZVI/MMT could produce significant RL. The RL of the as-prepared composites could be calculated using the following equation [44]:

$$
\begin{gathered}
\operatorname{RL}(\mathrm{dB})=20 \log \left|\left(\mathrm{Z}_{\text {in }}-1\right) /\left(\mathrm{Z}_{\text {in }}+1\right)\right| \\
\mathrm{Z}_{\text {in }}=\left(\mu_{\gamma} / \varepsilon_{\gamma}\right)^{1 / 2} \tanh \left[\mathrm{j}(2 \pi \pi \mathrm{f} / \mathrm{c})\left(\mu_{\gamma} \varepsilon_{\gamma}\right)^{1 / 2}\right]
\end{gathered}
$$

where $Z_{\text {in }}$ represents the normalized input impedance relating to the impedance in free space, $\mathrm{f}$ represents the frequency of microwave absorbing, $\mathrm{d}$ represents the thickness of the absorbing layer, $\mathrm{c}$ represents the velocity of electromagnetic wave in vacuum, and $\varepsilon_{\mathrm{r}}$ and $\mathrm{u}_{\mathrm{r}}$ represent the relative complex permittivity $\left(\varepsilon_{\mathrm{r}}=\varepsilon^{\prime}-\mathrm{j} \varepsilon^{\prime \prime}\right)$ and permeability $\left(\mu_{\mathrm{r}}=\mu^{\prime}-\mathrm{j} \mu^{\prime \prime}\right)$, respectively.

The microwave absorption of the dielectric loss and magnetic loss are two factors that affect RL. The ability to store electric and magnetic energy is a reaction to the real permittivity $\left(\varepsilon^{\prime}\right)$ and the real permeability $\left(\mu^{\prime}\right)$, while the dissipation of electric and magnetic energy is related to the imaginary permittivity $\left(\varepsilon^{\prime \prime}\right)$ and the imaginary permeability $\left(\mu^{\prime \prime}\right)[45]$. The dielectric loss (tan $\left.\delta e=\varepsilon^{\prime \prime} / \varepsilon^{\prime}\right)$ for nZVI/MMT gradually increases while magnetic loss $\left(\tan \delta \mu=\mu^{\prime \prime} / \mu^{\prime}\right)$ decreases gradually from 2 to $5 \mathrm{GHz}$ (Figure 3a). Both $\tan \delta$ e and $\tan \delta \mu$ stay at a relatively fixed value from 5 to $10 \mathrm{GHz}$. Therefore, dielectric loss plays a major role in controlling microwave absorption, and magnetic loss plays a minor role. Moreover, the value of the dielectric loss is higher than the magnetic loss, suggesting that dielectric loss contributes more to enhancing the microwave absorption properties of nZVI/MMT, rather than the magnetic loss.

(a)

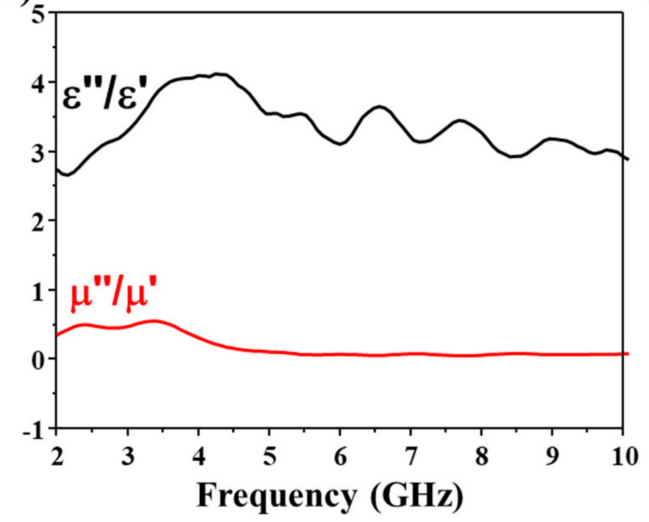

(b)

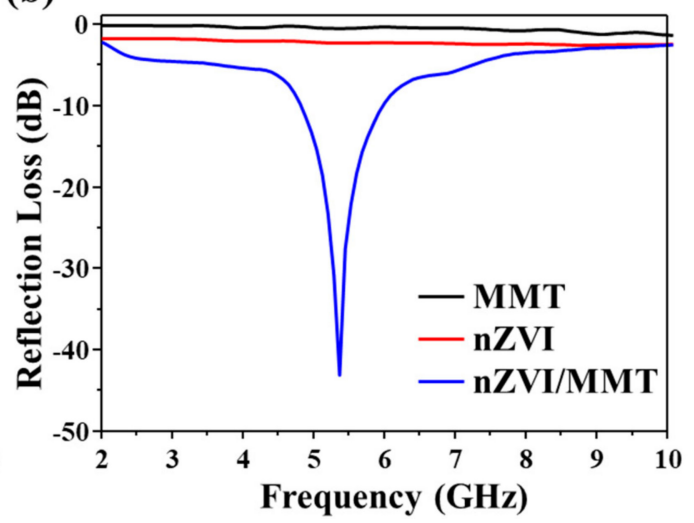

Figure 3. Relative complex permittivity and relative complex permeability's frequency dependence of nZVI/MMT (a), and reflection-absorption rate of MMT, nZVI and nZVI/MMT (b).

The RL values of nZVI and MMT are very close to 0 from 2 to $10 \mathrm{GHz}$, while the RL value of nZVI/MMT shows a strong absorbing peak at the frequency of $5.3 \mathrm{GHz}$ (Figure $3 \mathrm{~b}$ ). This means that nZVI/MMT had a much better microwave absorbing ability and could be used as an excellent microwave absorption material due to its high bandwidth and broad spectrum characteristics. 


\subsection{Degradation of Rh $6 G$ Using $n Z V I / M M T$}

Nano zero-valent iron can degrade many organic dyes using the following Fenton-like Reactions (3)-(5) $[46,47]$ because the produced $\bullet \mathrm{OH}$ and $\bullet \mathrm{O}_{2}{ }^{-}$have a strong degradation ability for a great majority of organic pollutants. Furthermore, the generated rate of the above free radicals can be improved under microwave treatment.

$$
\begin{gathered}
\mathrm{O}_{2}+\mathrm{Fe}^{0}+2 \mathrm{H}^{+} \rightarrow \mathrm{Fe}^{2+}+\mathrm{H}_{2} \mathrm{O}_{2} \\
\mathrm{Fe}^{2+}+\mathrm{H}_{2} \mathrm{O}_{2} \rightarrow \mathrm{Fe}^{3+}+\cdot \mathrm{OH}+\mathrm{OH}^{-} \\
\mathrm{Fe}^{2+}+\mathrm{O}_{2} \rightarrow \cdot \mathrm{O}_{2}^{-}+\mathrm{Fe}^{3+}
\end{gathered}
$$

The degradation ability for dyes of nZVI/MMT under microwave treatment was evaluated by removal of Rh 6G. We studied the effect of different initial concentrations of Rh $6 \mathrm{G}$ on the removal efficiency (Figure 4a). When the initial concentration of Rh 6G is less than $5000 \mathrm{mg} / \mathrm{L}$, the maximal removal amount of Rh 6G increases with the increase of the initial concentration of Rh 6G; when the initial concentration is larger than $5000 \mathrm{mg} / \mathrm{L}$, the maximal removal amount maintains at $500 \mathrm{mg} / \mathrm{g}$. Therefore, an optimal initial concentration of Rh $6 \mathrm{G}$ was set as $5000 \mathrm{mg} / \mathrm{L}$ in the rest of the experiments.

The effect of microwave power on the removal amount of Rh 6G by nZVI/MMT was investigated (Figure $4 \mathrm{~b}$ ). The degradation rate of Rh $6 \mathrm{G}$ gradually increases with the increase of microwave power as the increasing microwave power will accelerate the generation of free radicals. When the microwave power is $700 \mathrm{~W}$, the removal amount of $\mathrm{Rh} 6 \mathrm{G}$ reaches $500 \mathrm{mg} / \mathrm{g}$. We further performed experiments to investigate the effect of $\mathrm{pH}$ conditions on the removal amount of Rh 6G using nZVI/MMT (Figure 4c). Because the Fenton reagents are strongly affected by $\mathrm{pH}$, the degradation ability under acidic conditions is significantly better than that under alkaline conditions. When the $\mathrm{pH}$ is high, the generation of hydroxyl radicals is inhibited and the iron ions are precipitated as hydroxides, leading to a decline in degradation efficiency. In addition, $\mathrm{H}_{2} \mathrm{O}_{2}$ would be decomposed ineffectively under alkaline conditions.

The degradation abilities of Rh 6G (initial concentration of $5000 \mathrm{mg} / \mathrm{L}$ ) using nZVI, MMT, and nZVI/MMT composite were compared under a microwave power of $700 \mathrm{~W}$ (Figure $4 \mathrm{~d}$ ). The removal concentration of Rh 6G within $15 \mathrm{~min}$ using nZVI/MMT composite is $500 \mathrm{mg} / \mathrm{g}$, while it is $471 \mathrm{mg} / \mathrm{g}$ and $483 \mathrm{mg} / \mathrm{g}$ using MMT and nZVI, respectively, better than MMT on Rh 6G adsorption and nZVI degradation. The enhanced performance of nZVI/MMT composite mainly results from the uniform dispersion of the nZVI on the MMT, which prevents the oxidation of the nZVI. Therefore, MMT loaded nZVI composite is an effective treatment material for organic wastewater. The natural logarithm $\operatorname{Ln}\left(\mathrm{C}_{0} / \mathrm{C}\right)$ of Rh $6 \mathrm{G}$ at time (t) to the initial Rh $6 \mathrm{G}$ was plotted and linearly fitted (Figure $\left.4 \mathrm{e}\right)$, which reveals that it is the first order kinetics of oxidative degradation with a linear correlation coefficient of 0.9976 and the apparent reaction rate constant is $0.4365 \mathrm{~min}^{-1}$. As summarized in Figure $4 \mathrm{f}$, this reaction rate is significantly higher than previous reports using other removal methods for Rh 6G [48-52]. 
(a)

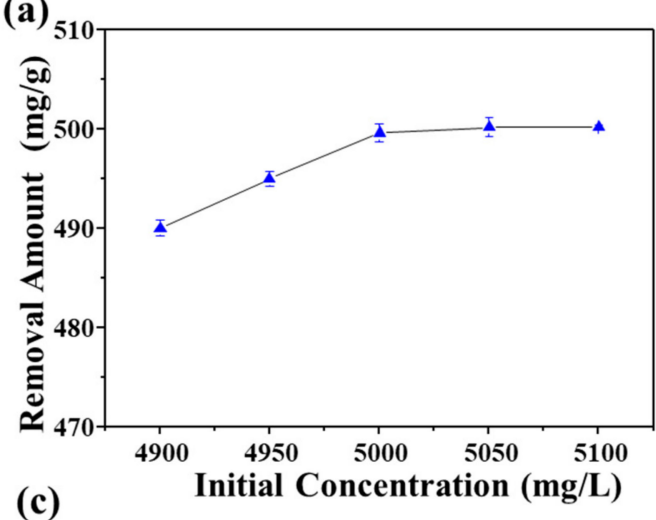

(c)

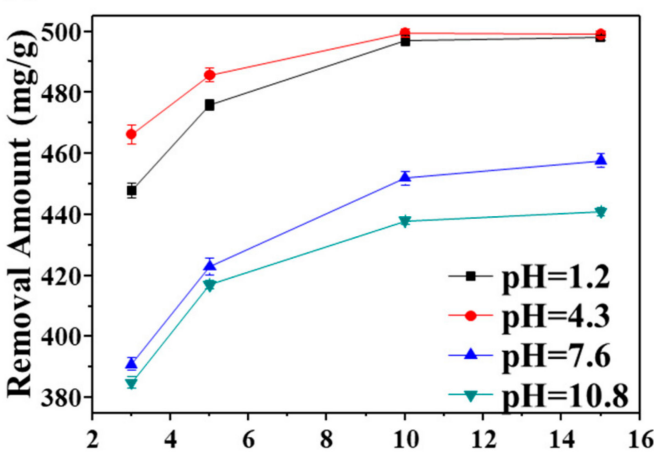

(e)

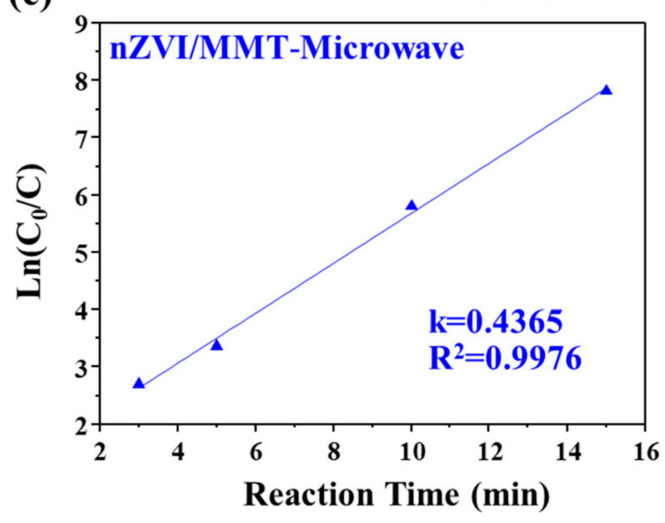

(b)

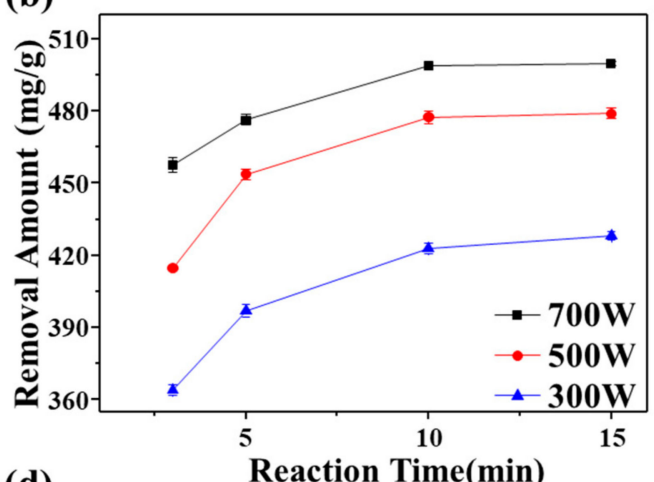

(d)

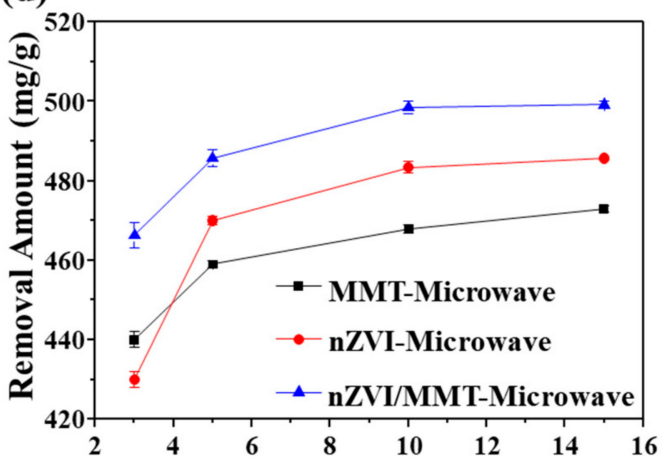

(f)

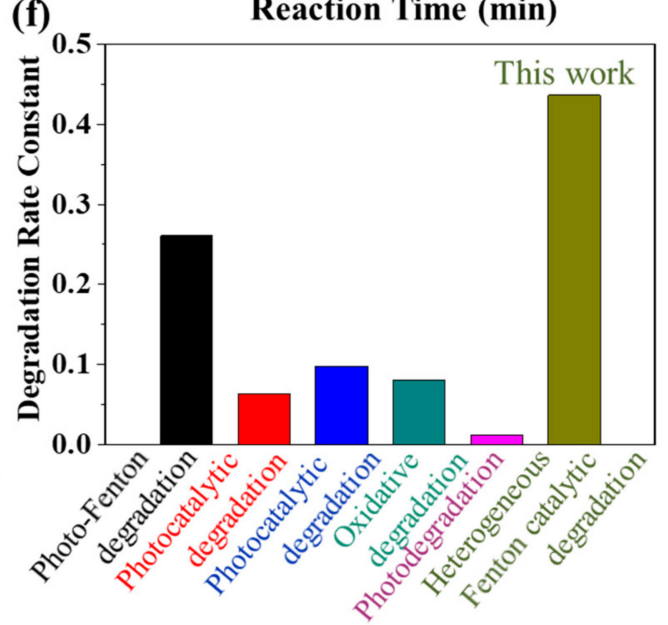

Figure 4. Removal amount of $\mathrm{Rh} 6 \mathrm{G}$ with the different initial concentration of $\mathrm{Rh} 6 \mathrm{G}(\mathbf{a})$, microwave power $(\mathbf{b})$, solution $\mathrm{pH}(\mathrm{c})$; removal amount of Rh 6G in the presence of MMT, nZVI and nZVI/MMT under microwave treatment (d); pseudo-first-order reaction model for Rh 6G removal by nZVI/MMT (e); and comparison of the reaction rates of different treating methods for removing Rh 6G (f).

The concentration of Rh 6G solution without nZVI/MMT did not change with the increase of reaction time under microwave treatment (Figure 5a). In contrast, the concentration of Rh 6G decreased significantly when nZVI/MMT was added (Figure $5 b$ ), and Rh 6G can be completely degraded at around $15 \mathrm{~min}$. 


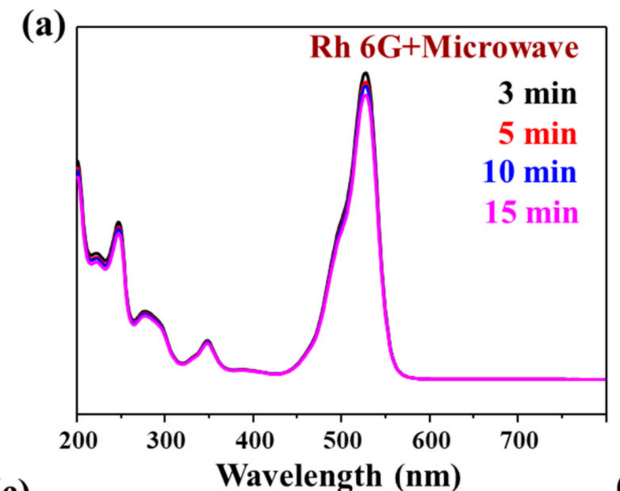

(b)

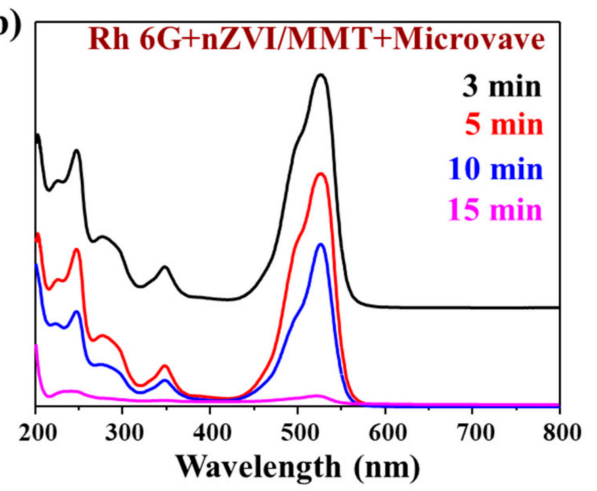

(d)

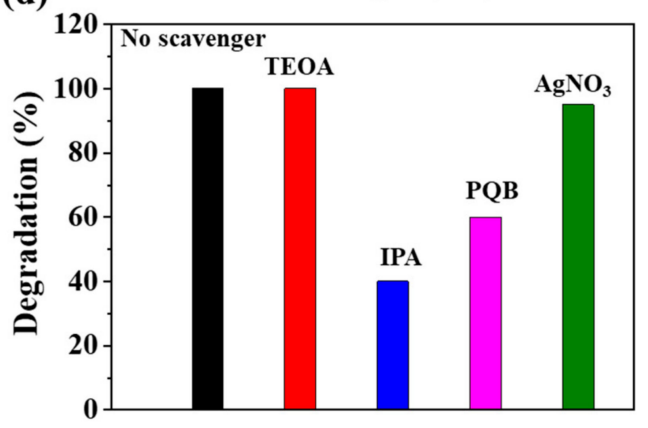

(c)

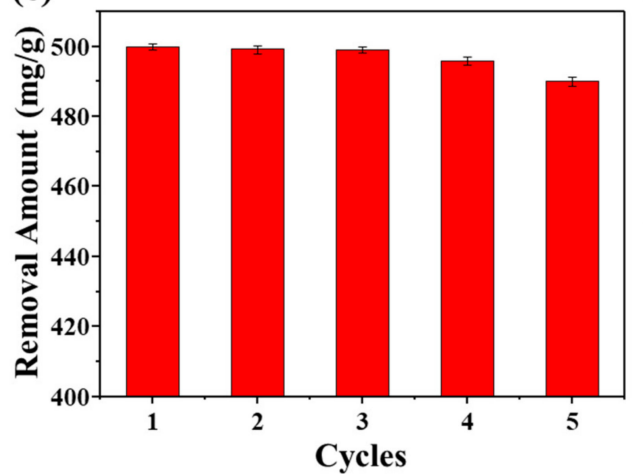

Figure 5. UV/Vis spectra of Rh 6G solution without nZVI/MMT after microwave for different time (a), with nZVI/MMT after microwave for different time (b), cycle stability test for nZVI/MMT (c), and degradation percentages of Rh 6G with different additives using nZVI/MMT under microwave treatment (d). Triethanolamine (TEOA), indolepropionic acid (IPA), p-benzoquinone (PBQ), and silver nitrate $\left(\mathrm{AgNO}_{3}\right)$.

The used composite material can be regenerated using $\mathrm{NaBH}_{4}$ to reduce $\mathrm{Fe}^{3+}$ as $\mathrm{Fe}^{0}$. Figure $5 \mathrm{c}$ shows the cyclability of the regenerated nZVI/MMT composite, and its removal rate can still remain more than $90 \%$ after five times of recycling, indicating that the prepared material can be reused several times.

As mentioned before, nZVI can activate the molecular oxygen in the solution under the treatment of microwaves to produce strong oxidizing radicals of $\bullet \mathrm{O}_{2}{ }^{-}$and $\bullet \mathrm{OH}$, and these active substances can lead to efficient oxidative degradation of organics. In order to study the role of these free radicals, same molar concentrations of indolepropionic acid (IPA), p-benzoquinone (PBQ), triethanolamine (TEOA), and silver nitrate $\left(\mathrm{AgNO}_{3}\right)$ were added to the Rh 6G solution during degradation. TEOA is a typical hole-trapping agent [53] and $\mathrm{AgNO}_{3}$ is a typical electron capturing agent [54]. Figure 5d displays the degradation percentages of $\mathrm{Rh} 6 \mathrm{G}$ with different additives, revealing that the degradation ability of $\mathrm{Rh} 6 \mathrm{G}$ gets worse with adding IPA or PQB, indicating that holes are not a key component in the degradation of $\mathrm{Rh} 6 \mathrm{G}$, and electrons have a weak effect on the degradation of $\mathrm{Rh} 6 \mathrm{G}$. Therefore, the number of $\bullet \mathrm{OH}$ or $\bullet \mathrm{O}_{2}{ }^{-}$radicals can greatly reduce in the $\mathrm{Rh}$ 6G degradation process after adding IPA or PQB scavengers, leading to the decrease of degradation ability of Rh 6G. The above results also confirm the essential role of $\bullet \mathrm{OH}$ or $\bullet \mathrm{O}_{2}{ }^{-}$in the degradation of Rh 6G using nZVI/MMT under microwave treatment.

\section{Conclusions}

In summary, a nZVI/MMT composite was synthesized by loading nZVI on MMT, showing better antioxidation ability than pure nZVI and strong microwave absorbing ability. The nZVI/MMT composite was further used to degrade Rh $6 \mathrm{G}$ under microwave treatment. As compared to $\mathrm{nZVI}$ and MMT, nZVI/MMT showed an excellent degradation ability for the removing of Rh 6G. For example, 
the corresponding removal amount reached $500 \mathrm{mg} / \mathrm{g}$ within $15 \mathrm{~min}$ and its degradation rate reached $0.4365 \mathrm{~min}^{-1}$, significantly higher than previous reports using other removal methods for Rh 6G. In addition, nZVI/MMT can be used several times with a slight decrease in the removal amount. With the usage of different scavengers, it was confirmed that the $\bullet \mathrm{O}_{2}{ }^{-}$and $\bullet \mathrm{OH}$ radicals were formed and played an important role during the Rh 6G degradation. The proposed nZVI/MMT composite in the present work demonstrated simplicity, flexibility, short reaction times, and high removal efficiency for organic dyes. Therefore, the prepared composite material has a good application prospect in wastewater treatment.

Author Contributions: D.W. and W.R. conceived the project. H.L., G.L., and L.L. designed the experiments. D.W., W.R., and G.L. analyzed the data. D.W. and W.R. wrote the manuscript.

Funding: This research was funded by the National Natural Science Foundation of China (51604248), the National Key R\&D Program of China (2017YFB0310704, 2017YFE0107000), and Fundamental Research Funds for the Central Universities (2652017338).

Conflicts of Interest: The authors declare no conflicts of interest.

\section{References}

1. Robinson, T.; Mcmullan, G.; Marchant, R.; Nigam, P. Remediation of dyes in textile effluent: A critical review on current treatment technologies with a proposed alternative. Bioresour. Technol. 2001, 77, $247-255$. [CrossRef]

2. Zhang, W.W.; Zhang, J.Y.; Chen, Z.Y.; Wang, T.M. Photocatalytic degradation of methylene blue by $\mathrm{ZnGa}_{2} \mathrm{O}_{4}$ thin films. Catal. Commun. 2009, 10, 1781-1785. [CrossRef]

3. Zhang, L.; Pan, F.; Liu, X.Y.; Yang, L.J.; Jiang, X.Q.; Yang, J.C.; Shi, W. Multi-walled carbon nanotubes as sorbent for recovery of endocrine disrupting compound-bisphenol F from wastewater. Chem. Eng. J. 2013, 218, 238-246. [CrossRef]

4. Wu, H.; Wang, S.; Kong, H.; Liu, T.; Xia, M. Performance of combined process of anoxic baffled reactor-biological contact oxidation treating printing and dyeing wastewater. Bioresour. Technol. 2007, 98, 1501-1504. [CrossRef] [PubMed]

5. Pearce, C.I.; Lloyd, J.R.; Guthrie, J.T. The removal of colour from textile wastewater using whole bacterial cells: A review. Dyes. Pigm. 2003, 58, 179-196. [CrossRef]

6. Rajkumar, D.; Kim, J.G. Oxidation of various reactive dyes with in situ electro-generated active chlorine for textile dyeing industry wastewater treatment. J. Hazard. Mater. 2006, 136, 203-212. [CrossRef] [PubMed]

7. Wang, S.; Chen, S.; Sun, D. Advances in the treatment of printing and dyeing wastewater by physical and chemical processes. Ind. Water Treat. 2010, 72, 227-242.

8. Kong, H.L.; Wu, H.F. A rapid determination method of chemical oxygen demand in printing and dyeing wastewater using ultraviolet spectroscopy. Water Environ. Res. 2009, 81, 2381-2386. [CrossRef] [PubMed]

9. Zhu, Z.Y.; Li, A.G.; Zheng, Y.C.; Jiao, Z. Study on Cleaning Methods of Membrane in Printing and Dyeing Wastewater by MBR. Adv. Mater. Res. 2013, 781-784, 1937-1940. [CrossRef]

10. Chen, S.; Wu, Y.; Li, G.; Wu, J.N.; Meng, G.H.; Guo, X.H.; Liu, Z.Y. A novel strategy for preparation of an effective and stable heterogeneous photo-Fenton catalyst for the degradation of dye. Appl. Clay Sci. 2017, 136, 103-111. [CrossRef]

11. Li, W.; Zhou, Q.; Hua, T. Removal of Organic Matter from Landfill Leachate by Advanced Oxidation Processes: A Review. Int. J. Eng. Res. 2010, 2010, 270532. [CrossRef]

12. Turchi, C.S.; Ollis, D.F. Photocatalytic degradation of organic water contaminants: Mechanisms involving hydroxyl radical attack. J. Catal. 1990, 122, 178-192. [CrossRef]

13. Chen, Z.; Xu, C.; Ma, C.; Ren, W.; Cheng, H. Lightweight and flexible graphene foam composites for high-performance electromagnetic interference shielding. Adv. Mater. 2013, 25, 1296-1300. [CrossRef] [PubMed]

14. Hansson, H.; Kaczala, F.; Marques, M.; Hogland, W. Photo-Fenton and Fenton Oxidation of Recalcitrant Industrial Wastewater Using Nanoscale Zero-Valent Iron. Int. J. Photog. 2012, 2012, 515-547. [CrossRef]

15. Liu, S.T.; Huang, J.; Ye, Y.; Zhang, A.B.; Pan, L.; Chen, X.G. Microwave enhanced Fenton process for the removal of methylene blue from aqueous solution. Chem. Eng. J. 2013, 215-216, 586-590. [CrossRef] 
16. Yeh, K.J.; Chen, T.C.; Young, W.L. Competitive Removal of Two Contaminants in a Goethite-Catalyzed Fenton Process at Neutral pH. Environ. Eng. Sci. 2013, 30, 47-52. [CrossRef]

17. Xu, L.; Wang, J. Degradation of 4-Chloro-3,5-Dimethylphenol by a Heterogeneous Fenton-Like Reaction Using Nanoscale Zero-Valent Iron Catalysts. Environ. Eng. Sci. 2013, 30, 294-301. [CrossRef] [PubMed]

18. Deng, J.M.; Dong, H.R.; Zhang, C.; Jiang, Z.; Cheng, Y.J.; Hou, K.J.; Zhang, L.H.; Fan, C.Z. Nanoscale zero-valent iron/biochar composite as an activator for Fenton-like removal of sulfamethazine. Sep. Purif. Technol. 2018, 202, 130-137. [CrossRef]

19. Ponder, S.M.; Darab, J.G.; Mallouk, T.E. Remediation of $\mathrm{Cr}(\mathrm{VI})$ and $\mathrm{Pb}(\mathrm{II})$ Aqueous Solutions Using Supported, Nanoscale Zero-valent Iron. Environ. Sci. Technol. 2000, 34, 2564-2569. [CrossRef]

20. Yu, R.F.; Chen, H.W.; Cheng, W.P.; Lin, Y.J.; Huang, C.L. Monitoring of ORP, pH and DO in heterogeneous Fenton oxidation using nZVI as a catalyst for the treatment of azo-dye textile wastewater. J. Taiwan Inst. Chem. Eng. 2014, 45, 947-954. [CrossRef]

21. Liu, T.Y.; Yang, Y.L.; Wang, Z.L.; Sun, Y.Q. Remediation of arsenic(III) from aqueous solutions using improved nanoscale zero-valent iron on pumice. Chem. Eng. J. 2016, 288, 739-744. [CrossRef]

22. Huang, P.P.; Ye, Z.F.; Xie, W.M.; Chen, Q.; Li, J.; Xu, Z.C.; Yao, M.S. Rapid magnetic removal of aqueous heavy metals and their relevant mechanisms using nanoscale zero valent iron (nZVI) particles. Water Res. 2013, 47, 4050-4058. [CrossRef] [PubMed]

23. Aduseigyamfi, J.; Acha, V. Carriers for nano zerovalent iron (nZVI): Synthesis, application and efficiency. RSC Adv. 2016, 6, 91025-91044. [CrossRef]

24. Singh, R.; Misra, V.; Singh, R.P. Remediation of $\gamma$-Hexachlorocyclohexane contaminated soil using nanoscale zero-valent iron. Bionanoscience 2011, 5, 82-87. [CrossRef]

25. Lai, B.; Zhang, Y.H.; Li, R.; Zhou, Y.X.; Wang, J. Influence of operating temperature on the reduction of high concentration p-nitrophenol (PNP) by zero valent iron (ZVI). Chem. Eng. J. 2014, 249, 143-152. [CrossRef]

26. El-Temsah, Y.S.; Joner, E.J. Effects of nano-sized zero-valent iron (nZVI) on DDT degradation in soil and its toxicity to collembola and ostracods. Chemosphere 2013, 92, 131-137. [CrossRef] [PubMed]

27. Hojeong, K.; Hong, H.J.; Juri, J.; Seonghye, K.; Yang, J.W. Degradation of trichloroethylene (TCE) by nanoscale zero-valent iron (nZVI) immobilized in alginate bead. J. Hazard. Mater. 2010, 176, 1038-1043.

28. Guler, U.A. Removal of tetracycline from aqueous solutions using nanoscale zero valent iron and functional pumice modified nanoscale zero valent iron. J. Environ. Eng. 2017, 25, 223-233. [CrossRef]

29. Zhang, Y.Y.; Jiang, H.; Zhang, Y.; Xie, J.F. The dispersity-dependent interaction between montmorillonite supported nZVI and Cr(VI) in aqueous solution. Chem. Eng. J. 2013, 229, 412-419. [CrossRef]

30. Gu, C.; Jia, H.; Li, H.; Teppen, B.J.; Boyd, S.A. Synthesis of Highly Reactive Subnano-Sized Zero-Valent Iron Using Smectite Clay Templates. Environ. Sci. Technol. 2015, 44, 4258-4263. [CrossRef] [PubMed]

31. Li, Z.; Chang, P.H.; Jean, J.S.; Jiang, W.T.; Hong, H. Mechanism of chlorpheniramine adsorption on Ca-montmorillonite. Colloids Surf. A Physicochem. Eng. Asp. 2011, 385, 213-218. [CrossRef]

32. Luptáková, V.; Horváth, I.; Perjéssy, A.; Putyera, K. IR Spectroscopic Study on Host-Guest Interaction of Montmorillonite with Benzothiazolium Compounds. Chem. Pap. 1992, 46, 157-161.

33. Gemeay, A.H. Adsorption Characteristics and the Kinetics of the Cation Exchange of Rhodamine-6G with $\mathrm{Na}^{+}$-Montmorillonite. J. Colloid Interface Sci. 2002, 251, 235-241. [CrossRef] [PubMed]

34. Lin, J.J.; Yang, C.Y.; Chou, C.C.; Su, H.L.; Hung, T.J. Stably-Dispersing Composite of Metal Nanoparticle and Inorganic Clay and Method for Producing the Same. US Application. US20090148484A1, 7 December 2007.

35. Tang, D.D.; Zhang, G.K. Fabrication of $\mathrm{AgFeO}_{2} / \mathrm{g}-\mathrm{C}_{3} \mathrm{~N}_{4}$ nanocatalyst with enhanced and stable photocatalytic performance. Appl. Surf. Sci. 2017, 391, 415-422. [CrossRef]

36. Fu, L.L.; Chen, Y.; Zhao, S.F.; Liu, Z.G.; Zhu, R.L. Sulfur-mediated synthesis of N-doped carbon supported cobalt catalysts derived from cobalt porphyrin for ethylbenzene oxidation. RSC Adv. 2016, 6, 19482-19491. [CrossRef]

37. Tokumura, M.; Znad, H.T.; Kawase, Y. Decolorization of dark brown colored coffee effluent by solar photo-Fenton reaction: Effect of solar light dose on decolorization kinetics. Water Res. 2008, 42, 4665-4673. [CrossRef] [PubMed]

38. Qiu, S.; Xu, S.; Li, G.; Yang, J. Synergetic Effect of Ultrasound, the Heterogeneous Fenton Reaction and Photocatalysis by $\mathrm{TiO}_{2}$ Loaded on Nickel Foam on the Degradation of Pollutants. Materials 2016, 9, 457. [CrossRef] [PubMed] 
39. Jiang, B.H.; Zhao, Y.; Jin, Y.; Hu, X.M.; Jiang, L.; Li, X.M. Study on Coupled Oxidation and Microwave Process in Treating Urban Landfill Leachate by Fenton and Fenton-like Reaction. Adv. Mater. Res. 2011, 393-395, 1443-1446. [CrossRef]

40. Cho, W.; Baek, Y.; Moon, S.K.; Kim, Y.C. Oxidative coupling of methane with microwave and RF plasma catalytic reaction over transitional metals loaded on ZSM-5. Catal. Today 2002, 74, 207-223. [CrossRef]

41. Olmedo, L.; Hourquebie, P.; Jousse, F. Microwave absorbing materials based on conducting polymers. Adv. Mater. 1993, 5, 373-377. [CrossRef]

42. Saines, P.J.; Paddison, J.A.M.; Thygesen, P.M.M.; Tucker, M.G. Searching Beyond Gd for Magnetocaloric Frameworks: Magnetic Properties and Interactions of the $\mathrm{Ln}\left(\mathrm{HCO}_{2}\right)_{3}$ Series. Mater. Horiz. 2015, 2, 528-535. [CrossRef]

43. Chen, J.; Xue, S.; Song, Y.T.; Shen, M.L.; Zhang, Z.H.; Yuan, T.X.; Tian, F.Y.; Dionysiou, D.D. Microwaveinduced carbon nanotubes catalytic degradation of organic pollutants in aqueous solution. J. Hazard. Mater. 2016, 310, 226-234. [CrossRef] [PubMed]

44. Liu, Y.; Zhao, K.; Drew, M.G.B.; Liu, Y. A theoretical and practical clarification on the calculation of reflection loss for microwave absorbing materials. AIP Adv. 2018, 8, 1-38.

45. Zhang, X.J.; Wang, G.S.; Cao, W.Q.; Wei, Y.Z.; Liang, J.F.; Guo, L.; Cao, M.S. Enhanced Microwave Absorption Property of Reduced Graphene Oxide (RGO)- $\mathrm{MnFe}_{2} \mathrm{O}_{4}$ Nanocomposites and Polyvinylidene Fluoride. ACS Appl. Mater. Interfaces 2014, 6, 7471-7478. [CrossRef] [PubMed]

46. Wu, Y.; Yang, M.; Hu, S.; Wang, L.; Yao, H. Characteristics and mechanisms of 4A zeolite supported nanoparticulate zero-valent iron as Fenton-like catalyst to degrade methylene blue. Toxicol. Environ. Chem. 2014, 96, 227-242. [CrossRef]

47. Huang, Z.; Chen, Y.; Hu, Y. The role of nanoscale zerovalent iron particles in the biosorption and biodegradation of BDE-47 by Pseudomonas stutzeri, under aerobic conditions. Int. Biodeterior. Biodegradat. 2016, 112, 51-58. [CrossRef]

48. Chen, Y.; Li, N.; Zhang, Y.; Zhang, L. Novel low-cost Fenton-like layered Fe-titanate catalyst: Preparation, characterization and application for degradation of organic colorants. J. Colloid Interface Sci. 2014, 422, 9-15. [CrossRef] [PubMed]

49. Natarajan, T.S.; Bajaj, H.C.; Tayade, R.J. Palmyra tuber peel derived activated carbon and anatase $\mathrm{TiO}_{2}$ nanotube based nanocomposites with enhanced photocatalytic performance in rhodamine 6G dye degradation. Process Saf. Environ. Prot. 2016, 104, 346-357. [CrossRef]

50. Cheng, Y.F.; Jiao, W.L.; Li, Q.Q.; Zhang, Y.; Li, S.S.; Li, D.D.; Che, R.C. Two hybrid Au-ZnO aggregates with different hierarchical structures: A comparable study in photocatalysis. J. Colloid Interface Sci. 2017, 509, 58-67. [CrossRef] [PubMed]

51. Huang, X.; Hu, W.; Niu, Y. Fe/ $\mathrm{Fe}_{3} \mathrm{C}$ nanoparticles loaded on $\mathrm{Fe} / \mathrm{N}$-doped graphene as an efficient heterogeneous Fenton catalyst for degradation of organic pollutants. Colloids Surf. A Physico. Chem. Eng. Asp. 2017, 518, 145-150. [CrossRef]

52. Ramírezaparicio, J.; Sánchezmartínez, A.; Ramírezbon, R. Photodecolorization of rhodamine under sunlight irradiation driven by chabazite. Sol. Energy 2016, 129, 45-53. [CrossRef]

53. Liu, X.L.; Yan, Y.; Da, Z.L.; Shi, W.D.; Ma, C.C.; Lv, P.; Tang, Y.F.; Yao, G.X.; Wu, Y.T.; Huo, P.W.; et al. Significantly enhanced photocatalytic performance of CdS coupled nanosheets and the mechanism study. Chem. Eng. J. 2014, 241, 243-250. [CrossRef]

54. Ibrahim, M.M.; Ahmed, S.A.; Khairou, K.S.; Mokhtar, M. Carbon nanotube/titanium nanotube composites loaded platinum nanoparticles as high performance photocatalysts. Appl. Catal. A Gen. 2014, 475, 90-97. [CrossRef]

(C) 2018 by the authors. Licensee MDPI, Basel, Switzerland. This article is an open access article distributed under the terms and conditions of the Creative Commons Attribution (CC BY) license (http:/ / creativecommons.org/licenses/by/4.0/). 